\title{
The Effect of Treatment of Coconut Fiber with Liquid Smoke on Mechanical Properties of Composite
}

\author{
$M$ Mukhlis*, Witono Hardi, Rulan Mustafa \\ Department of Mechanical Engineering, Faculty of Engineering Khairun University
}

\begin{abstract}
This study aims to determine the effect of liquid smoke treatment on the tensile strength of the single fiber and Coconut fiber (CF) Reinforced Composite. The research method is Immersion the fiber with liquid smoke and heating. First treatment, CF was immersed in liquid smoke for 1, 2, and 3 hours, then dried for 1 hour at a temperature of 40 degrees Celsius. Next, the single fiber tensile test was carried out with the Universal Impact Test Machine and composite impact strength. The results showed that the tensile strength of single fiber TP, P1J, P2J, and P3J of 51.357 MPa, 79.655 MPa, 48.187 MPa, and 58.117 MPa. While the CF composite impact test TP, P1J, P2J, and P3J of $0.514 \mathrm{KJ} / \mathrm{m}^{2}, 1.385 \mathrm{KJ} / \mathrm{m}^{2}, 1,085 \mathrm{KJ} / \mathrm{m}^{2}$, and $2,128 \mathrm{KJ} / \mathrm{m}^{2}$. The liquid smoke immersion can increase the tensile strength of single fibers, where 1-hour immersion has the greatest value. In contrast, the impact strength of the CF composites increased at 3 hours, the largest immersion value. The results showed that the fiber soaked in liquid smoke could be an alternative to improve the mechanical properties of $\mathrm{CF}$.
\end{abstract}

Keywords: liquid smoke, tensile strength, impact strength, coconut fiber.

\section{Introduction}

The development of research that utilizes renewable and biodegradable materials to replace metal materials is very rapid [1][2][3][4]. Researchers are currently focusing on non-metallic materials from fibrous plants because the fiber can be used as a composite reinforcement and is easy to obtain, inexpensive, and has mechanical properties [5][6], such as sago sheath fiber [6], bamboo fiber [7]., pineapple fiber [8], and palm fiber [9]

North Maluku, as one of the eastern provinces of Indonesia, is one area that has the potential to research natural fibers into composite reinforcement materials, where there are several studies on natural fibers that have been carried out in eastern Indonesia, including sago fiber, king pineapple fiber, fiber fibers, and others [10][9].

In the series of studies mentioned above, treatments were carried out to improve micro and macro properties, including physical properties and mechanical properties, as for some of the treatments carried out by soaking the fibers with chemical liquids such as treatment with alkali [11][12][13] and non-chemicals such as turmeric liquid [14], liquid smoke [10], and fumigation [8].

The potential of using Coconut Fiber (CF) originated from the island of Ternate, North Maluku, eastern Indonesia, as a composite reinforcement. The fiber is the outermost part of the coconut fruit. The coconut belt consists of an outermost layer (exocarpium) and an inner layer (endocarpium). Endocarpium contains fine fibers that can be used as composite reinforcement [15].

The treatment material uses liquid smoke, which results from the pyrolysis process of natural ingredients such as coconut shell, which has the same content as fiber consisting of lignin, hemicellulose, and cellulose [2]. Liquid smoke can change the material texture [16] and the texture of natural fibers [10]. Increase in tensile strength of single fiber on 1-hour liquid smoke immersion [6]. Liquid smoke can change the chemical and thermal properties of the fiber [17], and liquid smoke is also antimicrobial [18][19], which can inhibit the potential for microbial growth on the fiber so that it inhibits fiber damage in its use.

\section{Methodology}

The material used is coconut coir fiber, which is taken from Ternate City, North Maluku Province. The research method was carried out by soaking the fiber in liquid smoke in a container with variations in immersion time of 1, 2, 3 hours, and without treatment. After that, it was dried in a dryer/oven at $40^{\circ} \mathrm{C}$ for 30 minutes. Then the fiber is cut to a length of $9 \mathrm{~cm}$, and a test specimen is made with the addition of paper and glue. While in the Impact Test Specimen, the material used is YUKALAC $15798 \%$ resin, $2 \%$ fiber with a fiber length of $4 \mathrm{~cm}$, and a catalyst then mixed in a container and then poured into a composite mold until hardened and then made into

\footnotetext{
*Corresponding author : mukhlis@yahoo.com
} 
specimens. Then a single fiber tensile test and an impact test were carried out.

Table 1. Research Notation

\begin{tabular}{|l|l|l|l|}
\hline No & Notation & $\begin{array}{l}\text { Notation } \\
\text { Code }\end{array}$ & Treatment \\
\hline $\mathbf{1}$ & No Treatment & TP & No Recognition \\
\hline $\mathbf{2}$ & 1 hour immersion & PJ1 & Liquid smoke \\
\hline $\mathbf{3}$ & 2 hours Immersion & PJ2 & Liquid smoke \\
\hline $\mathbf{4}$ & 3 hours Immersion & PJ3 & Liquid smoke \\
\hline
\end{tabular}

\subsection{Single Fiber Tensile Test}

The single fiber tensile test specimen uses the ASTM D3379-75 standard. The Single fiber testing is carried out by preparing test materials that have passed the specimen manufacturing process. Set the tensile test equipment according to the data to be taken. Install the specimen and then operate the test equipment until the fiber is cut off, record the test results, or save the test equipment readings' test results.

\subsection{Impact Test Specimen}

The impact test specimen uses the ASTM D256-02 standard. Impact testing is carried out by preparing test materials that have passed the specimen manufacturing process according to the ASTM D256-02 standard. After the impact test, equipment is per the data taken. Then, install the specimen, operate the impact test equipment until the specimen breaks, record the test results, or save the test equipment readings.

\section{Result and Discussion}

The results showed the effect of coco fiber treatment on the tensile strength of single fiber and the impact strength of the composite with variations without immersion, immersion 1, 2 and 3 hours.

\subsection{Single Fiber Tensile Test}

Table 2. Single fiber tensile strength relationship data with Liquid Smoke Treatment

\begin{tabular}{|c|c|c|}
\hline No & Treatment & $\begin{array}{c}\text { Average Tensile } \\
\text { Strength }\end{array}$ \\
\hline $\mathbf{1}$ & TP & 51,357 \\
\hline $\mathbf{2}$ & P1J & 79,655 \\
\hline $\mathbf{3}$ & P2J & 48,187 \\
\hline $\mathbf{4}$ & P3J & 58,117 \\
\hline
\end{tabular}

The data on the average tensile strength of single fiber showed that TP tensile strength of $51,357 \mathrm{MPa}$, then it increased significantly at P1J of 79,655 MPa, P2J of immersion experienced a decrease in tensile strength of $48,187 \mathrm{MPa}$, and $\mathrm{P} 3 \mathrm{~J}$ of immersion it increased of $58.117 \mathrm{MPa}$.

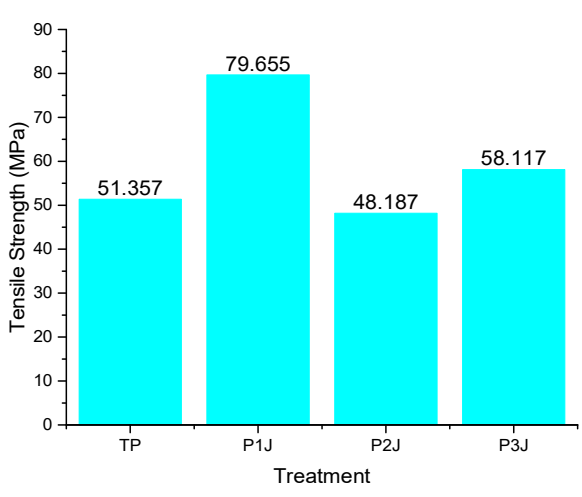

Fig.1. Graph of the relationship between immersion time and tensile strength

Types of fiber variations in treatment and without treatment where the immersion of coconut coir fiber with liquid smoke experienced a significant increase in tensile strength in P1J of $79.655 \mathrm{MPa}$ from that TP of $51.357 \mathrm{MPa}$, while at $\mathrm{P} 2 \mathrm{~J}$ decreased tensile strength of 48.187 MPa and P3J the tensile strength increased by $58.117 \mathrm{MPa}$. The average tensile test of coir fiber with the largest tensile strength in the 1-hour liquid smoke immersion treatment and the smallest tensile strength in the 3-hour liquid smoke immersion. The graph above shows that liquid smoke immersion can increase the tensile strength of single fibers at 1-hour immersion.

\subsection{Impact Test}

Table 3. Data on the Relationship of Specimen Fiber Treatment to Impact Strength

\begin{tabular}{|c|c|c|}
\hline No & Treatment & $\begin{array}{c}\mathbf{K J} / \mathbf{m}^{\mathbf{2}} \text { Average impact } \\
\text { strength }\end{array}$ \\
\hline $\mathbf{1}$ & TP & 0.514 \\
\hline $\mathbf{2}$ & P1J & 1.385 \\
\hline $\mathbf{3}$ & P2J & 1.085 \\
\hline $\mathbf{4}$ & P3J & 2,128 \\
\hline
\end{tabular}

The impact test results of TP, P1J, P2J, and P3J have an average strength $\mathrm{TP}$ of $0.514 \mathrm{KJ} / \mathrm{m}^{2}, \mathrm{P} 1 \mathrm{~J}$ of 1.385 $\mathrm{KJ} / \mathrm{m}^{2}$ has increased, $\mathrm{P} 2 \mathrm{~J}$ is $1.085 \mathrm{KJ} / \mathrm{m}^{2}$ has decreased, and the immersion for $\mathrm{P} 3 \mathrm{~J}$ increased by $2.128 \mathrm{KJ} / \mathrm{m}^{2}$.

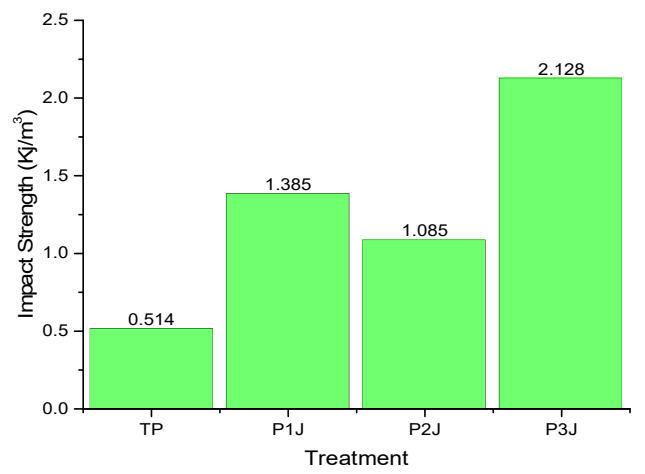

Fig.2. Graph of the relationship between Immersion Time Impact Strength 
In the type of treatment variation and $\mathrm{TP}$ where the immersion of coconut coir fiber with liquid smoke increases the impact strength, the $\mathrm{P} 1 \mathrm{~J}$ shows an increase in the mechanical properties of the impact strength of $1.385 \mathrm{KJ} / \mathrm{m}^{2}$ from that TP of 0.514 . In comparison, the P2J experiences a decrease of $1,085 \mathrm{KJ} / \mathrm{m}^{2}$ and an increase of $2.128 \mathrm{KJ} / \mathrm{m}^{2}$ on immersion for P3J. Thus, the graph above shows that soaking coconut coir fiber with liquid smoke can increase the mechanical properties of the impact strength. This is due to an increase in the tensile strength of a single fiber so that the coconut belt fiber, when used as a composite reinforcement, will increase the impact strength.

Figures 1 and 2 also show that the tensile strength of the coconut belt fiber is directly proportional to the impact strength of the coconut belt reinforced composite, where the tensile and impact strengths in $\mathrm{P} 1 \mathrm{~J}$ increase from the tensile and impact strengths without treatment. In addition, the increase and decrease in tensile and impact strength are the same where P2J decreases and in P3J treatment increases. However, in general, the treated coconut fibers experienced an increase in mechanical properties compared to those that were not treated.

Changes affect the increase in tensile and impact strength on the compound bond of coconut belt fibers with liquid smoke, where there is a carbon bond (CC) in the fiber [17], resulting in an increase in the strong, attractive force between the carbon elements.

Improving the mechanical properties of coconut belt fibers due to liquid smoke treatment is one solution in increasing the strength of coconut fibers so that they can be used as an option in the manufacture of coconut belt fiber-reinforced composites. Coconut fiber-reinforced composites are becoming a new choice in the manufacture of composite material products

\section{Conclusion}

1. Effect of treatment of liquid smoke on the tensile strength of the single fiber in which the test results showed the tensile strength TP to $51.357 \mathrm{MPa}, \mathrm{P} 1 \mathrm{~J}$ increased tensile strength is significant for 79.655 $\mathrm{MPa}$. In contrast, the $\mathrm{P} 2 \mathrm{~J}$ decreased strength tensile testing of a single fiber of $48,187 \mathrm{MPa}$ and increased tensile strength again at P3J of 58,117 $\mathrm{MPa}$. It can be concluded that the lowest tensile strength of a single fiber is liquid smoke immersion for 2 hours of $48.187 \mathrm{MPa}$, and the highest tensile strength of a single fiber is the immersion of liquid smoke for 1 hour of $79.655 \mathrm{MPa}$

2. The effect of treatment of coconut coir fiber with smoke seeking can increase the impact strength of the test results show the average impact strength TP of $0.514 \mathrm{KJ} / \mathrm{m}^{2}$ in $P 1 \mathrm{~J}$ increase of $1.385 \mathrm{KJ} / \mathrm{m}^{2}$, while in $\mathrm{P} 2 \mathrm{~J}$ of coconut fiber composite decreased of $1.085 \mathrm{KJ} / \mathrm{m}^{2}$ and P3J of liquid smoke immersion of coconut fiber composite increased of 2.128 $\mathrm{KJ} / \mathrm{m}^{2}$. Therefore, it can be concluded that the lowest impact strength is fiber composite TP of $0.514 \mathrm{KJ} / \mathrm{m}^{2}$, and the highest impact strength is fiber composite with $\mathrm{P} 3 \mathrm{~J}$ of $2.128 \mathrm{KJ} / \mathrm{m}^{2}$.

\section{References}

[1] S. S. Chee, M. Jawaid, M. T. H. Sultan, O. Y. Alothman, and L. C. Abdullah, "Thermomechanical and dynamic mechanical properties of bamboo/woven kenaf mat reinforced epoxy hybrid composites," Compos. Part B Eng., vol. 163, pp. 165-174, (2019).

[2] W. Ashraf, M. R. Ishak, M. Z. M.Y., N. Yidris, and A. M. Ya'acob, "Effect on mechanical properties by partial replacement of the glass with alkali-treated flax fiber in the composite facesheet of sandwich structure," J. Mater. Res. Technol., 2021.

[3] M. H. Gheith et al., "Flexural, thermal and dynamic mechanical properties of date palm fibres reinforced epoxy composites," J. Mater. Res. Technol., vol. 8, no. 1, pp. 853-860, (2019).

[4] T. M. Loganathan et al., "Physico-mechanical and Flammability Properties of Cyrtostachys renda Fibers Reinforced Phenolic Resin Bio-composites," $J$. Polym. Environ., (2021).

[5] M. Asim, M. Jawaid, H. Fouad, and O. Y. Alothman, "Effect of surface modified date palm fibre loading on mechanical, thermal properties of date palm reinforced phenolic composites," Compos. Struct., vol. 267, p. 113913, (2021).

[6] M. Muslimin, kusno Kamil, S. A. S. Budi, and I. Wardana, "Effect of liquid smoke on surface morphology and tensile strength of Sago Fiber," $J$. Mech. Eng. Sci., vol. 13, no. 4, pp. 6165-6177, (2019).

[7] M. Rasheed, M. Jawaid, and B. Parveez, "Preparation, Characterization and Properties of Biodegradable Composites from Bamboo FibersMechanical and Morphological Study," J. Polym. Environ., (2021).

[8] M. B. Palungan, R. Soenoko, and F. Gapsari, "The effect of king pineapple leaf fiber (Agave Cantala Roxb) fumigated toward the fiber wettability and the matrix epoxy interlocking ability," EnvironmentAsia, vol. 12, no. 3, pp. 129-139, (2019).

[9] Mardin, I. N. G. Wardana, W. Suprapto, and K. Kamil, "Effect of Sugar Palm Fiber Surface on Interfacial Bonding with Natural Sago Matrix," vol. 2016, (2016)

[10] M. Muslimin, S. A. S, W. I. N. G, and K. Kamil, "Liquid Smoke Potential Solution on Texture and Bonding Sago Fiber- Matrix Liquid Smoke Potential Solution on Texture and Bonding Sago FiberMatrix," vol. 494, (2019).

[11] L. Yan, N. Chouw, L. Huang, and B. Kasal, "Effect of alkali treatment on microstructure and mechanical properties of coir fibres, coir fibre reinforcedpolymer composites and reinforced-cementitious composites," Constr. Build. Mater., vol. 112, pp. 168-182, (2016).

[12] M. N. Norizan, K. Abdan, M. S. Salit, and R. Mohamed, "The effect of alkaline treatment on the mechanical properties of treated sugar palm yarn fibre reinforced unsaturated polyester composites reinforced with different fibre loadings of sugar palm fibre," Sains Malaysiana, vol. 47, no. 4, pp. 699-705, (2018).

[13] M. Pouriman, A. R. Caparanga, M. Ebrahimi, and A. Dahresobh, "Characterization of Untreated and Alkaline-Treated Salago Fibers (Genus Wikstroemia Spp.)," J. Nat. Fibers, vol. 15, no. 2, pp. 296-307, Mar. (2018).

[14] I. Renreng, R. Soenoko, pratikto, and Y. Surya Irawan, "Effect Of Turmeric (Curcuma) Solution 
Treatment Toward The Interfacial Shear Stress And Wettabilty Of A Single Fiber Akaa (Corypha) On Epoxy Matrix," Int. J. Appl. Eng. Res. ISSN, vol. 10, no. 10, pp. 973-4562, (2015).

[15] M. Arsyad, "Effect of alkali treatment on the coconut fiber surface," ARPN J. Eng. Appl. Sci., vol. 12, no. 6, pp. 1870-1875, (2017).

[16] S. Berhimpon, R. I. Montolalu, H. A. Dien, F. Mentang, and A. U. I. Meko, "Concentration and application methods of liquid smoke for exotic smoked Skipjack (Katsuwonus pelamis L.)," Int. Food Res. J., vol. 25, no. 5, pp. 1864-1869, (2018).

[17] M. Muslimin, K. Kamil, S. A. S, and W. I. N. G., "Effects of Liquid Smoke on the Chemical Composition and Thermal Properties of Sago Fiber," J. SOUTHWEST JIAOTONG Univ., vol. 54, no. 1, pp. 1-11, (2019).

[18] M. Faisal and A. Gani, "The effectiveness of liquid smoke produced from palm kernel shells pyrolysis as a natural preservative in fish balls," Int. J. GEOMATE, vol. 15, no. 47, pp. 145-150, (2018).

[19] M. Faisal, T. Chamzurni, and H. Daimon, "A study on the effectiveness of liquid smoke produced from palm kernel shells in inhibiting black pod disease in cacao fruit in vitro," Int. J. GEOMATE, vol. 14, no. 43, pp. 36-41, (2018). 